\title{
Regenerating Lettuce from Suspension Culture in a 2-Liter Bioreactor
}

\author{
Whei-Lan Teng', Chiao-Po Lin, and Yann-Jiun Liu \\ Agricultural Biotechnology Division, Development Center for Biotechnology, \\ 81 Chang Hsing Street, Taipei, Taiwan, Republic of China \\ Additional index words. Lactuca sativa, fermentor, wall effect, dissolved oxygen
}

eneacetic acid. The $\mathrm{pH}$ of the medium was adjusted to 5.8 before autoclaving.

A 2-liter, polypropylene bioreactor was designed and constructed specifically for this study. The bioreactor was equipped with an agitation controller and automatic water supply system (Fig. la). All of its tubing (aeration pipes, water supply pipe, and inoculation pipe) was made of autoclavable silicone and Teflon. Air was channeled to the medium by bubbling. The water loss from evaporation due to such aeration was replenished by the automatic water supply system, where the $\mathrm{pH}$ of water was adjusted to 5.8 before autoclaving. Water instead of SH medium was added for such replenishment, because adding $\mathrm{SH}$ medium would raise the overall ion concentration. Water was added automatically to the water supply system (Fig. 1a) at a rate equal to the water evaporation rate; thus, a constant level of medium was maintained. Although not precisely measured, water replenishment rate depended on aeration rate and was estimated at 0.5 to 1.2 liters over the 2 -week culture period.

A two-blade propeller installed in the bioreactor's center was used for mixing the culture medium and inoculum. Since the

Recently, adventitious shoots have been encapsulated and used for artificial seeds in crops (such as lettuce) for which somatic embryogenesis protocols are not available (Morimoto, 1991; Redenbaugh et al., 1991). Bioreactor culture has been investigated by Kirin Brewery (one of Japan's largest biotechnology companies) as a means to scale up shoot production (Morimoto, 1991). However, scale up of plant propagation using bioreactors is still a field with few published articles (e.g., Akita nd Takayama, 1988; Chen et al., 1987; Greidziak et al., 1990, Levin et al., 1988; Park et al., 1989; Preil et al., 1988; Stuart et al., 1987; Takayama et al., 1991). In most cases, mass propagation systems in bioreactors still are not developed fully for practical application.

In establishing a bioreactor culture system, certain factors, which are generally of less concern with flask culture, become important, including foaming, the wall effect, dissolved oxygen (DO) concentration, $\mathrm{pH}$ changes, and shear force. In general, regeneration in 1- to 2liter bioreactors is $<100$ somatic embryos $/ \mathrm{ml}$ culture medium; this amount is lower than that in 125- to 250-ml flasks (Kessell and Carr, 1972; Stuart et al., 1987). The conversion rate of somatic embryos regenerated in bioreactors is also lower than that in flasks. For example, alfalfa (Medicago sativa L.) somatic embryo

Received for publication 2 Oct. 1992. Accepted for publication 27 Jan. 1993. This research was supported by the U.S. Dept. of Agriculture and Council of Agriculture in Taiwan, project no. TW-AES-42. The cost of publishing this paper was defrayed in part by the payment of page charges. Under postal regulations, this paper therefore must be hereby marked advertisement solely to indicate this fact. 'To whom reprint requests should be addressed. regeneration in a bioreactor was $2 \%$ to $3 \%$ compared with $30 \%$ in flasks (Stuart et al., 1987).

In experiments using poinsettia (Euphorbia pulcherrima Wind. et K1.) suspension culture, foaming and the wall effect were prevented by bubble-free aeration (Preil, 1991; Preil et al., 1988). Based on previous research, optimal DO for somatic embryogenesis varies significantly among species (Beck, 1987; Kessell and Carr, 1972; Preil et al., 1988; Stuart et al., 1987). For example, 80 alfalfa somatic embryos were regenerated per milliliter of culture medium from a bioreactor with $70 \%$ DO, whereas no embryos formed in medium with $21 \%$ DO (Stoat-t et rd., 1987). One hundred poinsettia somatic embryos per milliliter of culture medium were produced with a constant 60\% DO (Beck, 1987; Preil et al., 1988). DO >16\% significantly inhibited carrot (Daucus carota L.) somatic embryogenesis (Kessell and Carr, 1972).

In a previous paper, we reported on a lettuce cell suspension culture system in flasks (Teng et al., 1992). Here we report on a suspension culture in a 2-liter bioreactor, where the adventitious shoot regeneration level is as high as that in 125 -ml flasks.

The in vitro 'Great Lake 118' lettuce culture was described in detail by Teng et al. (1992). Callus was subculture every other week. Inoculum for the bioreactor culture was prepared by blending green callus (with adventitious buds) with liquid culture medium for $60 \mathrm{sec}$. The inoculum, composed of single cells and aggregates of a few cells, was sufficiently small to pass through $400-\mu \mathrm{m}$ (42mesh) stainless steel sieves. The liquid culture medium was Schenk and Hildebrandt $(\mathrm{SH})$ (1972) basal medium supplemented with $1.5 \%$ glucose, $100 \mathrm{mg}$ myo-inositol/liter, 0.44 мм6benzyladenine, and $0.54 \mu \mathrm{M} \alpha$ naphthal-

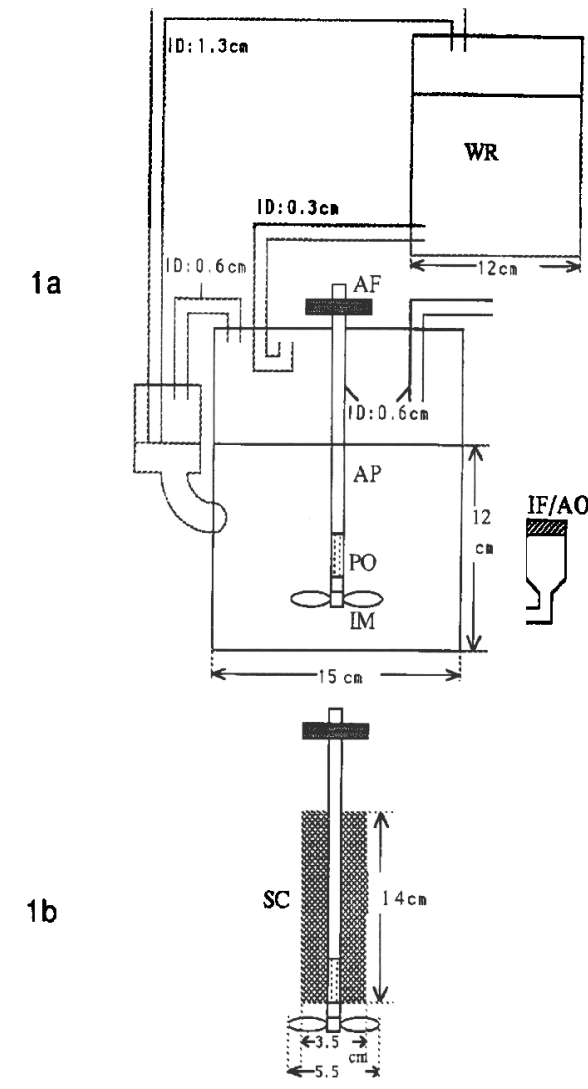

Fig. 1. (a) Schematic diagram of the bioreactor. Dashed lines represent an automatic water supply system. $\mathrm{AF}=$ air filter, $\mathrm{AP}=$ aeration pipe, $\mathrm{IF} / \mathrm{AO}=$ inoculation funnel/air outlet, IM = impeller, PO =pipe opening (short dashed lines), $\mathrm{WR}=$ water reservoir, ID = inside diameter. (b) Simple aeration apparatus using screen column (SC) to isolate aeration from inoculum. The screen column has two closed ends, and one end is above the medium level. 


\section{BiotechNology}

bioreactor was not equipped with an on-line DO monitor, DO was measured off-line using a DOmeter (model YSI 58; Yellow Springs Instrument Co., Yellow Springs, Ohio) equipped with a DO probe (model YSI 5730).

Before autoclaving, the bioreactor was charged with 1.8 liters of culture medium. During inoculation, $200 \mathrm{ml}$ inoculum with a density of 15 to $17 \mathrm{mg}$ dry wt of plant cells $/ \mathrm{ml}$ medium was added through an inoculation funnel; the final volume in the bioreactor was 2 liters (Fig. la). Only the inoculation funnel was in the air flow of the laminar clean-air bench during inoculation because, once it was installed, medium contamination, which often existed without the inoculation funnel, was eliminated. The final inoculation density in the bioreactor was 3.0 to $3.4 \mathrm{~g}$ dry wt of cells/ 2 liters medium. After inoculation, the bioreactor was agitated at $110 \mathrm{rpm}$ in a culture room at $25 \mathrm{C}$ under continuous light of 8 $\mu \mathrm{mol} \cdot \mathrm{m}^{-2} \cdot \mathrm{s}^{-1}$. The culture medium was not replaced during the 14-day culture period (time required for most inoculum to regenerate).

Flask culture also was conducted in 125$\mathrm{ml}$ flasks to compare its adventitious shoot regeneration level with that in the bioreactor culture. All inoculated flasks were placed on an orbital shaker at $110 \mathrm{rpm}$ in the same culture room. Since a flask contained only $30 \mathrm{ml}$ culture medium and the bioreactor contained 2 liters culture medium, the regeneration level was based on the number of shoots $/ 30 \mathrm{ml}$ culture medium.

To establish lettuce suspension culture in a 2-liter bioreactor, factors that influence cell growth and differentiation were tested, including foaming, the wall effect, and aeration rate. All experiments were conducted three times.

At the initial stage of the bioreactor culture, a large amount of foam was generated when air was introduced into the mixture of inoculum and culture medium. As a result, inoculum adhered onto the vessel wall above the medium level; i.e., the wail effect (Fig. 2). During the first day of culture, the loss of inoculum due to the wall effect could be as high as $10 \%$. The inoculum adhering on the wall turned from green to brown in a few days. Such inoculum did not regenerate shoots. At an aeration rate of $1 \mathrm{vvm}$ (1 liter air/1 liter medium per rein), the regeneration rate was 54 shoots/30 ml culture medium.

In industrial microbial fermentation and plant cell culture, foaming can be reduced by applying antifoaming agents. In this study, however, applying an anti foaming agent (Pluronic PE 6100; BASF, West Germany) increased foaming.

Foaming could be prevented by removing single cells, cell debris, and the contents of broken cells from the inoculum. This was accomplished bypassing the inoculum through a 235- $\mu$ m (80-mesh) stainless steel sieve, then rinsing the inoculum thoroughly with distilled water.

Although sieving eliminated foaming, the wall effect still existed. We found that it resulted from bubbles generated by aeration. Small bubbles caused more cells to adhere to the vessel than large bubbles; the wall effect was worse as the amount of bubbles increased. Different types of propellers were tried at different locations in the vessel (at different distances from the medium surface and the wall), but none proved effective in preventing the wall effect. A screen column made of polyester was inserted to isolate the inoculum from the aeration area so that aeration was restricted in the column (Fig. lb). This effectively eliminated the wall effect.

The larger the mesh openings of the screen column, the more effective the circulation of aerated and nonaerated medium; however, once the mesh opening became too large, bubbles emerged from the column. A screen column with $150-\mu \mathrm{m}$ (115-mesh) openings was selected to test the optimal aeration rate.

Screen column location in the bioreactor also made a difference in shoot regeneration level. For screen columns located in the center and next to the wall (side) of the bioreactor, the number of shoots regenerated at an aeration rate of 1 vvm was 202 and 127 shoots $/ 30 \mathrm{ml}$, respectively (Table 1 ). When the screen column was at the side, inoculum adhered to the screen column and settled on the bottom of the bioreactor near the column. Most of this inoculum did not regenerate adventitious shoots. This disadvantage could be overcome by locating the screen column in the center of the bioreactor, where the highest regeneration occurred at an aeration rate of 1 to $2 \mathrm{vvm}$, which was similar to that in flasks (Table 1).

Flask culture was chosen to measure DO changes during the 14-day culture period under a high regeneration system. The original DO after inoculation was $90 \%$. It declined slightly during the first week and continued to decline to $15 \%$ on day 10 , when most adventitious shoots became visible. DO then increased up to $80 \%$ as shoots elongated (Fig. 3).

In the bioreactor, DO at the end of the culture period ranged from $71 \%$ to $89 \%$ at an aeration rate of 1 to $3 \mathrm{vvm}$ (Fig. 4). The number of regenerated shoots was the highest at $70 \%$ to $80 \%$ DO (Table 1, Figs. 3 and 4).

Three types of regenerated adventitious shoots were obtained from bioreactor culture: normal, vitrified, and semi-vitrified (Fig. 5).

Table 1. Influence of screen column location and aeration rate on lettuce regeneration in a 2-liter bioreactor. The regeneration of the control flask was $184 \pm 25$ shoots $/ 30 \mathrm{ml}$ culture medium with $59 \pm 14$ shoots $>0.5 \mathrm{~cm}$.

\begin{tabular}{|c|c|c|c|c|}
\hline \multirow{3}{*}{$\begin{array}{l}\text { Aeration }^{2} \\
(\mathrm{vvm})\end{array}$} & \multicolumn{4}{|c|}{ Shoots/30 ml (no.) } \\
\hline & \multicolumn{2}{|c|}{ Total } & \multicolumn{2}{|c|}{$>0.5 \mathrm{~cm}$} \\
\hline & Center & Side & Center & $\overline{\text { Side }}$ \\
\hline$\overline{0.4}$ & 33 & --- & 11 & $\overline{---}$ \\
\hline 1 & 202 & 127 & 45 & 0 \\
\hline 2 & 209 & 234 & 50 & 0 \\
\hline 3 & 144 & 55 & 21 & 0 \\
\hline \multicolumn{5}{|c|}{ Significance } \\
\hline $\begin{array}{l}\text { Linear } \\
\mathrm{Q} \text { u a d }\end{array}$ & $\begin{array}{l}\text { NS } \\
\mathrm{t} \text { i c }\end{array}$ & ${ }_{*}^{\mathrm{NS}}$ & $\begin{array}{r}\text { NS } \\
*\end{array}$ & $\begin{array}{r}\mathrm{NS} \\
\mathrm{NS}\end{array}$ \\
\hline
\end{tabular}

${ }^{2}$ Liters air/liters medium per min.

${ }^{y}$ Center $=$ screen column located in the center, side $=$ next to the wall of the bioreactor.

"Nonsignificant or significant at $P \leq 0.05$ or 0.01 , respectively.

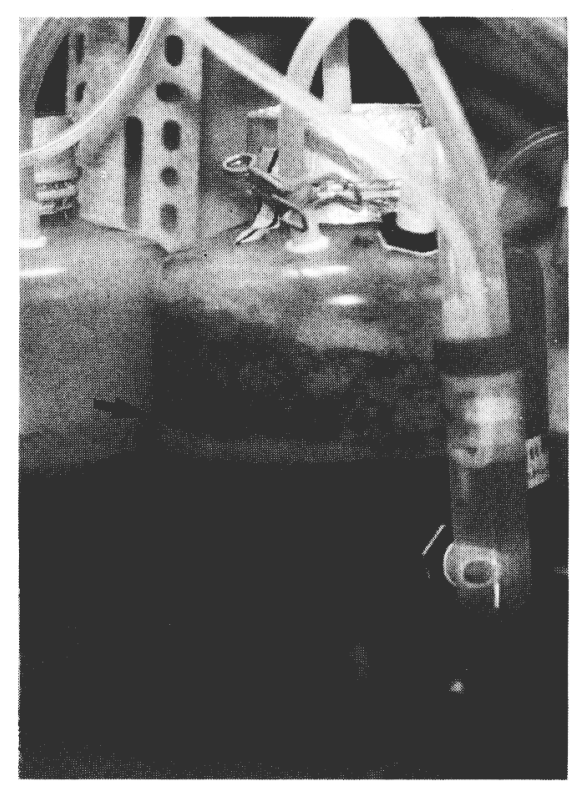

Fig. 2. The wall effect caused by inoculum that adhered onto the vessel wall above the medium level. Arrow points to foam and brown inoculum.

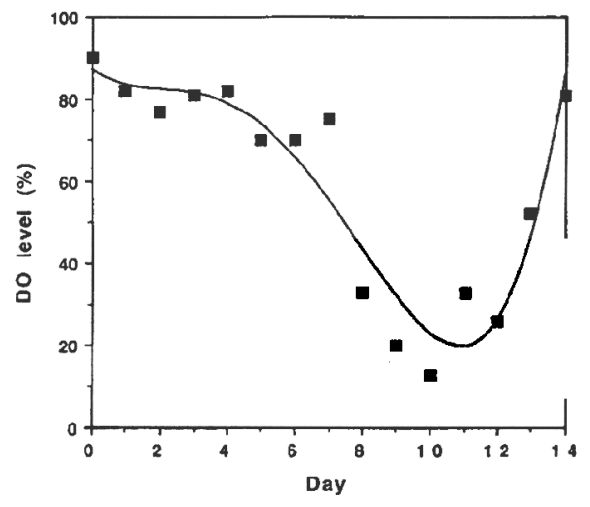

Fig. 3. Changes in dissolved oxygen (DO) concentration during the 14-day culture period in a flask; $y=87.125-5.9593 x+2.9032 x^{2}-$ $0.57140 \mathrm{x}^{3}+2.8650 \mathrm{x}-2 \mathrm{x}^{4}, R^{2}=0.895$.

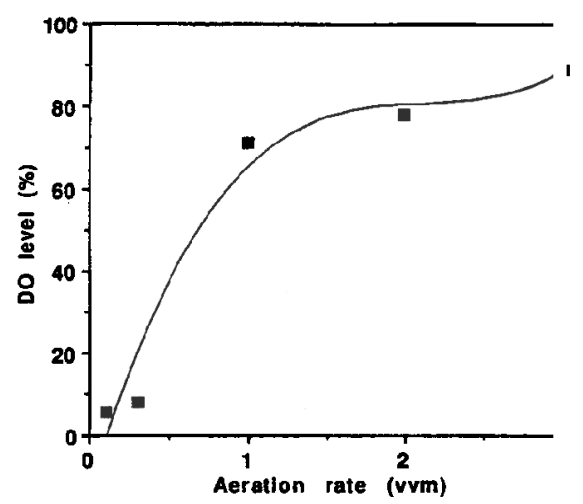

Fig. 4. Changes in dissolved oxygen (DO) concentration at the end of the culture period in a 2-liter bioreactor at various aeration rates. The screen column was located in the center of the bioreactor; $\mathrm{y}=(-14.387)+130.67 \mathrm{x}-60.737 \mathrm{x}^{2}+9.5385 \mathrm{x}^{3}$, $R^{2}=0.964$. 
Most of them did not have roots. Adventitious shoot rooting took place on solid $\mathrm{SH}$ basal medium. Of these three types, vitrified shoots were the most difficult to root. However, they could regenerate adventitious shoots if transferred to the same culture medium as the one used in this study, but with added agar. Semivitrified shoots with the callus on shoot bases and leaves were thicker than normal shoots and could form roots, but the time required was much longer than that for normal shoots. Normal and semi-vitrified plantlets mew in a hydroponic system, but vitrified plantlets did not.

These results seem promising for mass propagation of lettuce in a bioreactor. To optimize the culture conditions for maximum regeneration, it is necessary to investigate further whether factors such as $\mathrm{pH}$ and DO should be maintained at a constant level because, in flask culture, $\mathrm{pH}$ and DO levels vary during the culture period. Shear force is another factor yet to be investigated; e.g., in poinsettia bioreactor culture, the propeller had to be replaced by a vibrating plate because the cells were sensitive to shear force (Preil, 1991; Preil et al., 1988).

\section{Literature Cited}

Akita, M. and S. Takayama. 1988. Mass propagation of potato tubers using jar fermenter techniques. Acts Hort. 230:55-61.

Beck, A. 1987. Untersuchungen zur somatischen Embryogeneses unter verschiedenen Bioreaktorbedingungen, insbesondere bei $\mathrm{Eu}$ phorbia pulcherrima Diplomarbeit. Fachbereich Biologic, Univ. Hamburg. p. 1-103.

Chen, T.H.H., B.C. Thompson, and D.F. Gerson.

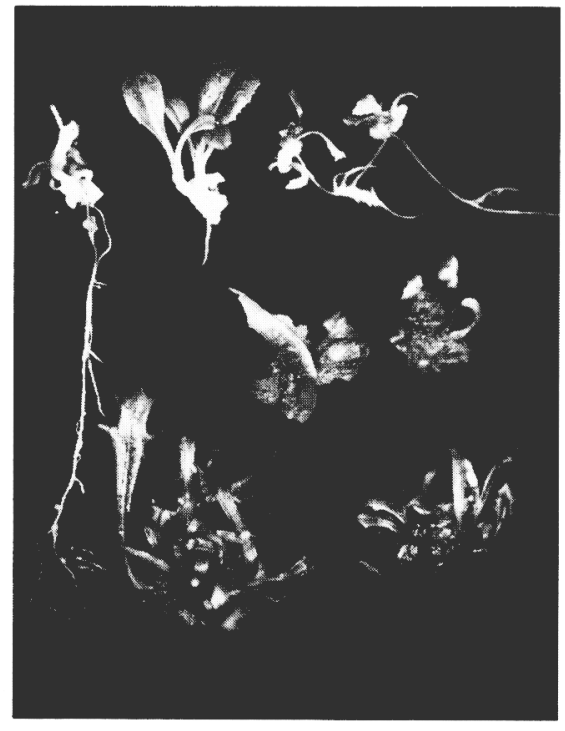

Fig. 5. Lettuce plantlets regenerated from bioreactor culture after being transferred to solid $\mathrm{SH}$ basal medium. (top row) Normal plantlets with roots, (center row) vitrified shoots, (bottom row) semi-vitrified shoots.

1987. In vitro production of alfalfa somatic embryos in fermentation systems. J. Fermentation Technol. 65:353-357.

Greidziak, W., B. Diettrich, and M. Luckner. 1990. Batch cultures of somatic embryos of Digitalis lanata in gaslift fermenters. Development and cardenolide accumulation. Planta Medics 56:175-178.

Kessell, R.H.J. and A.H. Carr. 1972. The effect of dissolved oxygen concentration on growth and differentiation of carrot (Daucus carota) tissue cultures. J. Expt. Bet. 23:996-1007.
Levin, R., V. Gaba, B. Tal, S. Hirsch, D. De Nola, and I.K. Vasil. 1988. Automated plant tissue culture for mass propagation. Bio/Technology 61035-1040.

Morimoto, K. 1991. Japanese biotechnology, p. 113. In: Biotechnology business development workshop. Dev. Ctr. Biotechnol., Taipei, Taiwan.

Park, J.M., W.S. Hu, and E.J. Staba. 1989. Cultivation of Artemisia апnиa L. plantlets in a bioreactor containing a single carbon source and a single nitrogen source-under submerged culture conditions, potential application to artemisinin production. Biotechnol. Bioeng. 34:1209-1213.

Preil, W. 1991. Application of bioreactor in plant propagation, p. 425-445. In: P.C. Debergh and R.H. Zimmerman (eds.). Micropropagation. Kliewer Academic, Boston.

Preil, W., P. Florek, U. Wix, and A. Beck. 1988. Towards mass propagation by use of bioreactors. Acts Hort. 226:99-105.

Redenbaugh, K., J.A. Fujii, and D. Slade. 1991. Synthetic seed technology, p. 7-35. In: I.K. Vasil (ed.). Cell culture and somatic cell genetics of plants. vol. 8. Scale-up and automation in plant propagation. Academic, New York.

Schenk, R.V. and A.C. Hildebrandt. 1972. Medium and techniques for induction and growth of monocotyledonous and dicotyledonous plant cell cultures. Can. J. Bet. 50:199-204.

Stuart, D.A., S.G. Strickland, and K.A. Walker. 1987. Bioreactor production of alfalfa somatic embryos. HortScience 22:800-809.

Takayama, S., B. Swedlund, and Y. Miwa. 1991. Automated propagation of microbulbs of lilies, p. 112-132. In: I.K. Vasil (ed.). Cell culture and somatic cell genetics of plants. vol. 8. Scale-up and automation in plant propagation. Academic, New York.

Teng, W.L., Y.J. Liu, and T.S. Soong. 1992. Rapid regeneration of lettuce from suspension culture. HortScience 27:1030-1032. 